\title{
Interactions between inflammatory mediators in expression of antitumor cytostatic activity of macrophages
}

\author{
I. L. Bonta ${ }^{1}$ and S. Ben-Efraim ${ }^{2}$ \\ ${ }^{1}$ Department of Pharmacology, Faculty of Medicine, Erasmus University, Rotterdam, The Netherlands, and ${ }^{2}$ Department of \\ Human Microbiology, Sackler School of Medicine, Tel-Aviv University, Tel-Aviv, Israel
}

(Received 31 March 1990; accepted 3 June 1990)

\section{Summary}

Antitumor properties and participation in inflammatory events are important characteristics of activated macrophages. We show here that both antitumor cytostatic function of macrophages and participation of these cells at inflammatory sites are controlled by two main groups of mediators: cytokines (IL-1, TNF $\alpha$ ) and eicosanoids (prostanoids and leukotrienes). These two groups of mediators represent a complex system of mutual interactions in regulation of their production and activities.

Multiple sets of experiments with murine macrophages are discussed in favor of the views that $\mathrm{PGE}_{2}$ and lipoxygenase products oppose each other's actions, and that the regulating role of $\mathrm{PGE}_{2}$ in the secretions of cytokines are of pivotal importance in antitumor cytostasis of macrophages in vitro. Such observations can be extended to a situation ex vivo, showing that human macrophages harvested from inflammatory sites have markedly augmented cytostatic expression. It thus appears that the antitumor cytostatic function of macrophages is related to the production of inflammatory mediators by these cells. Accordingly, it might be that occurrence of inflammation in tumor-bearing individuals plays a role in the promotion of antitumor activity of macrophages.

Key words: Macrophages; Antitumor cytostasis; Mediator of inflammation; Eicosanoid; Cytokine

Correspondence to: I. L. Bonta, Dept. of Pharmacology, Faculty of Medicine, Erasmus University, P.O. Box 1738, 3000 DR Rotterdam, The Netherlands

\section{Introduction}

The concept that phagocytic cells play a role in the defense of the organism against foreign intruders was first elaborated by Metchnikoff in 1901 [1]. Later [2], Metchnikoff claimed also that macrophages are activated in response to an inflammatory challenge. Such activated macrophages were found to exhibit high antitumor cytotoxic response [3].

Extensive work was done with the aim to determine the mechanism(s) of macrophage activation. A recent review [4] summarizes the data on cytotoxic activities of macrophages. The macrophage can react nonspecifically against a wide array of cells, including tumor cells. The antitumor potential of quiescent macrophages is hardly appreciable, but with activated macrophages the expression of cytostatic and/or cytocidal effects toward tumor cells is rather pronounced $[3,4]$. Macrophagemediated antitumor cytostasis can be defined as the inhibition of tumor cell division and can be distinguished from the cytocidal effect [4]. The antitumor function of macrophages may comprise two mechanisms, existing separately or concomitantly: (a) cell-to-cell contact between macrophages and tumor cells; (b) discharge of factors which attack target cells. Among these factors, interleukin-1 (IL1) and tumor necrosis factor (TNF $\alpha$ ) are now recognized as mediators of inflammation [5]. Furthermore, IL-1 is implicated in regulating the discharge of $\mathrm{PGE}_{2}$ and of leukotrienes (LTs) [6], which are eicosanoid mediators of inflammation. The modulatory role of $\mathrm{PGE}_{2}$ in opposing the effect of LTs on the involvement of macrophages in the inflammato- 
ry process was proposed several years ago [7]. Similarly, interactions between eicosanoids and cytokines (IL-1, TNF $\alpha$ ), contribute to the regulation of macrophage and monocyte functions [4]. Because the activation state of the macrophage is of pivotal importance for the role of this cell in both events (inflammation and defence against tumors), the mediators of inflammation which are involved in the activation of macrophages may constitute the link between the two events.

This minireview is based mainly on the data obtained in our laboratories during the last six years on the role of macrophage inflammatory mediators (cytokines and eicosanoids) in the expression of antitumor cytostatic activity, with special emphasis on the interactions between various macrophage products. This in view of the fact that cytokines and eicosanoids (leukotrienes and prostaglandins) regulate their own and each other's release. It is not within the scope of this article to discuss all the vast literature on the various activities of macrophages and/or inflammatory mediators. In this context, the reader is referred to extensive, detailed reviews published in recent years $[4-6]$.

\section{Eicosanoids and cytokines regulate their own and each other's release}

Eicosanoids, products of arachidonic acid (AA) metabolism, feed back onto the macrophage and modulate their own release. The observation that IL1 interferes with the release of lipoxygenase products [8], renders the situation even more complicated. Table 1 is an attempt to provide a guide in the complexity of events. The most salient points can be highlighted as follows. The earlier knowledge that the release of $\mathrm{LTB}_{4}$ is enhanced by stimulation of calcium flux by A23187 and reduced by inhibitors of lipox-

TABLE 1

Autoregulation of mediator release from macrophages.

\begin{tabular}{|c|c|c|}
\hline \multirow[t]{2}{*}{ Released product } & \multicolumn{2}{|c|}{ Effect of exogenous compound on release } \\
\hline & Increase by & Decrease by \\
\hline $\begin{array}{l}\text { Peptidoleukotrienes } \\
\left(\mathrm{LTC}_{4} \text { or } \mathrm{LTD}_{4}\right) \\
\mathrm{LTB}_{4}{ }^{\mathrm{a}}\end{array}$ & $\begin{array}{l}\text { IL-1 }[8] \\
\text { A23187 }[10,11] \\
\text { Aspirin, indomethacin }[10]\end{array}$ & $\begin{array}{l}\text { db-cAMP [10] } \\
\text { PGE }_{2}[10] \\
\text { AA861 [11]; } \\
\text { NDGA [9] }\end{array}$ \\
\hline $\mathrm{PGE}_{2}$ & $\mathrm{LTC}_{4}, \operatorname{LTD}_{4}[12,13]$ & db-cAMP [14] \\
\hline $\mathrm{PGI}_{2}{ }^{\mathrm{b}}$ & $\begin{array}{l}\text { LTD [12] } \\
\text { A23187 [11] }\end{array}$ & $\mathrm{PGE}_{2}, \mathrm{db}-\mathrm{cAMP}[14]$ \\
\hline $\mathrm{TxA}_{2}{ }^{\mathrm{c}}$ & $\begin{array}{l}\text { LTD [12] } \\
\text { A23187 [11] }\end{array}$ & $\begin{array}{l}\mathrm{PGE}_{2}, \mathrm{db}-\mathrm{cAMP} \\
{[14,10]}\end{array}$ \\
\hline ILI $^{\mathrm{d}}$ & $\begin{array}{l}\mathrm{LTB}_{4}[16] ; \text { TNF } \alpha[18] \\
\text { LPS [34] } \\
\text { Indomethacin } \\
\text { piroxicam, ibuprofen [15] }\end{array}$ & $\begin{array}{l}\mathrm{PGE}_{2}[15] ; \mathrm{PGI}_{2} \\
{[15]}\end{array}$ \\
\hline $\mathrm{TNF} \alpha^{\mathrm{d}}$ & $\begin{array}{l}\text { LPS [19]; low conc. } \mathrm{PGE}_{2}{ }^{\mathrm{e}} \\
\text { [20] }\end{array}$ & $\begin{array}{l}\text { High conc. } \mathrm{PGE}_{2}{ }^{\mathrm{f}} \text {, } \\
{[20]}\end{array}$ \\
\hline
\end{tabular}

\footnotetext{
a Basal level is below detection level; A23187-induced stimulation of calcium flux is used to promote release for investigating regulatory events. ${ }^{b}$ Measured as the metabolite 6-keto-PGF ${ }_{1 \alpha^{*}}{ }^{\mathrm{c}}$ Measured as $\mathrm{TxB}_{2} .{ }^{\mathrm{d}}$ LPS-stimulated release is used to measure regulatory influences. ${ }^{\mathrm{e}}<10 \mathrm{ng} / \mathrm{ml}$. ${ }^{\mathrm{f}}>10 \mathrm{ng} / \mathrm{ml}$. Inhibition of release of cyclooxygenase products by aspirin, indomethacin, etc., is textbook knowledge and omitted from this table.
} 
ygenase, has now been extended with the observation that $\mathrm{PGE}_{2}$ counteracts the discharge of lipoxygenase products. This effect of $\mathrm{PGE}_{2}$ is mediated through elevation of intracellular cyclic AMP, which reduces the amount of free AA available to different enzymes, including lipoxygenase. Nonsteroidal antiinflammatory drugs (NSAIDs), through removal of the regulatory effect of $\mathrm{PGE}_{2}$, promote the release of lipoxygenase metabolites [9-11]. Furthermore, LTs were shown to promote the release of cyclooxygenase metabolites, $\mathrm{PGE}_{2}$ included $[12,13]$. In the view that $\mathrm{PGE}_{2}$ would in turn inhibit the release of LTs [10], the action of the latter is a homeostatic selflimiting process. $\mathrm{PGE}_{2}$-induced elevation of intracellular cyclic AMP and the mimicry of this event by exogenous dibutyryl cAMP decreases not only the calcium flux enhancement of $\mathbf{L T B}_{4}$, but also that of cyclooxygenase metabolites [14]. Accordingly, the eicosanoid secreting function of macrophages is positively related to the activity of the lipoxygenase pathway and in negative relation to the synthesis viz. discharge of the cyclooxygenase metabolite $\mathrm{PGE}_{2}$ : LTs enhance the release of eicosanoids (thus mimicking the effect of A23187), whereas $\mathrm{PGE}_{2}$ suppresses this event. The concept of $\mathrm{PGE}_{2}$

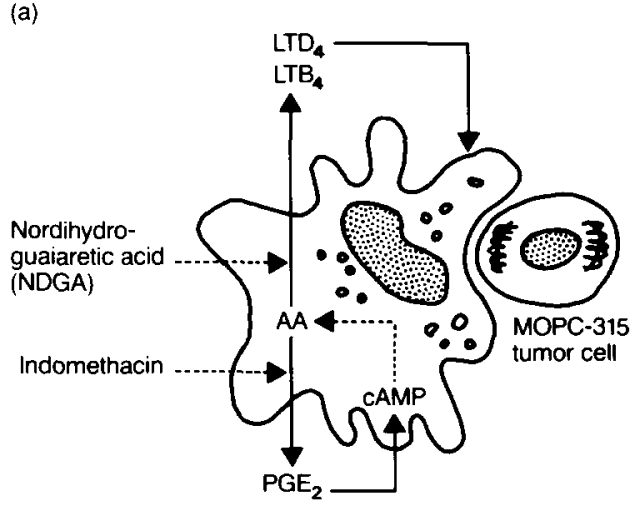

and lipoxygenase metabolites being each other's opponents in macrophage function takes on new dimensions in the light of recent findings which show that LPS-stimulated secretion of IL-1, itself a stimulator of $\mathrm{PGE}_{2}$ production [15], is promoted by $\mathrm{LTB}_{4}$ and $\mathrm{LTD}_{4}$ [16]. NSAIDs were reported to enhance the discharge of IL-1, conceivably through removing endogenous $\mathrm{PGE}_{2}$ [15]. But others showed that $\mathrm{PGE}_{2}$ has no effect on IL-1 production, but interferes with the bioassay of IL-1 [17]. Besides the homeostatic negative feedback that involves eicosanoids controlling their own release and their mutual interaction with the release of IL-1, it appears that there is a regulatory circle between cytokines as well. At least, TNF $\alpha$ was shown to enhance the release of IL-1 [18], whereas LPS stimulates the producion not only of IL-1, but also of TNF $\alpha$ [19]. However, $\mathrm{PGE}_{2}$ has a dual effect on TNF $\alpha$ secretion, low doses having a stimulatory influence and high concentrations suppressing this event [20]. This would indicate that $\mathrm{PGE}_{2}$ regulation of $\mathrm{TNF} \alpha$ secretion is dissimilar to $\mathrm{PGE}_{2}$ control of IL discharge. However, the low concentrations of $\mathrm{PGE}_{2}$, having caused increased production of $\mathrm{TNF} \alpha$, were not examined for their effect on IL-1 secretion. Accordingly, a dual

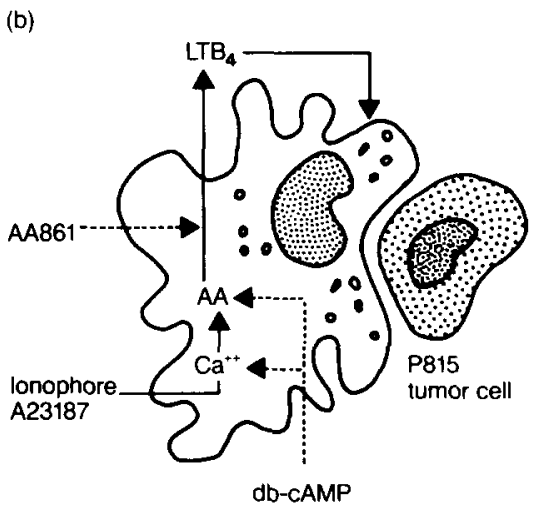

Fig. 1. Solid arrows, stimulatory influences; broken arrows, inhibitory influences. (a) Lipoxygenase products either added exogenously

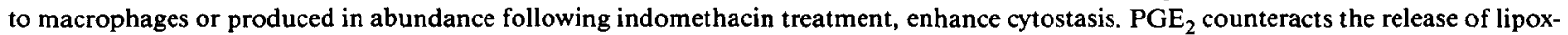
ygenase products and accordingly inhibits the cytostatic function. This effect of $\mathrm{PGE}_{2}$ is mediated through elevation of intracellular cyclic AMP which reduces the amount of arachidonic acid (AA) available to different enzymes, including lipoxygenase. Thus, $P G E_{2}$ reduces the release of $\mathrm{LTB}_{4}$ and other leukotrienes. Indomethacin, through removal of PGE and accordingly enhances cytostasis. The indomethacin-enhanced cytostasis is counteracted by NDGA-induced inhibition of lipoxygenase. For original papers see $[9,10,23]$. (b) Stimulation of calcium flux by A23187 enhances the cytostatic function of macrophages toward tumor cells. This effect of $\mathbf{A} 23187$ is mediated via release of $\mathbf{L T B}_{4}$, which promotes cytostasis. The specific lipoxygenase inhibitor AA861 counteracts both the release of $\mathrm{LTB}_{4}$ and cytostasis. Calcium flux stimulates phospholipase activity, resulting in enlarged amounts of free AA. Mimicry of endogenous cyclic AMP by exogenous dibutyryl cyclic AMP (db-cAMP) counteracts the effect of the calcium ionophore. In similarity to indomethacin-enhanced cytostasis, also the calcium flux-enhanced cytostasis requires a promoted release of lipoxygenase products. For original papers see $[10,11,22]$. 
effect of $\mathrm{PGE}_{2}$ on IL-1 secretion cannot be excluded. Furthermore, macrophages also release cytostatic factors other than IL-1 or TNF $\alpha$ [21]. It is not known whether the release of these other factors is under the control of eicosanoids. Nevertheless, to understand the cytokine-eicosanoid regulation of the macrophage cytostatic function, the network as discussed above may serve as a blueprint, as will be shown in the sections which follow.

\section{Lipoxygenase pathway favors cell-to-cell contact cytostasis}

Increasing evidence has accumulated during the last few years indicating that the antitumor activity of macrophages in a cell-to-cell contact system is regulated by eicosanoid products $[9,11,22,23]$. These results were obtained by co-culturing macrophages with target cells. A pitfall of this method might be the release by macrophages of a soluble factor which inhibits uptake of thymidine by target cells while not affecting their rate of proliferation [24]. However, we used as target cells the murine tumor cell lines MOPC-315 plasmacytoma and P815 mastocytoma, which were susceptible only to direct contact with macrophages but not to their soluble products. The role of leukotrienes in promotion of antitumor cytostasis by macrophages is illustrated in Fig. 1a and b. Treatment of macrophages with in- domethacin (which promotes LTB $_{4}$ production [10]), or exogenous addition of LTs $\left(\mathrm{LTD}_{4}\right.$ or $\left.\mathrm{LTB}_{4}\right)$ to co-cultures of macrophages and tumor cells enhanced the antitumor cytostasis by macrophages, whereas a lipoxygenase inhibitor (NDGA) prevented the antitumor activity (Fig. 1a). Stimulation of calcium flux by the calcium ionophore A23187 enhanced both cytostatic function of macrophages and release of $\mathrm{LTB}_{4}$, whereas both release of $\mathrm{LTB}_{4}$ and cytostasis were prevented by the specific lipoxygenase inhibitor AA861 (Fig. 1b). On the other hand, mimicry of endogenous cyclic AMP (increased production related to increase in prostaglandin biosynthesis) by exogenous dibutyryl cyclic AMP (db-cAMP), counteracts the effect of $\mathrm{A} 23187$ in induction of cytostasis.

\section{Interactions between cytokines and eicosanoids on tumor cell growth}

The antitumor activity of macrophage cytokines IL-1 and of TNF $\alpha$ is well established $[3,25,26]$. We found that the murine WEHI-3B tumor was highly sensitive to IL-1 [27] and less sensitive to TNF $\alpha$. The availability of a tumor-cell sensitive to cell-free macrophage cytokines, allowed us to investigate interactions between cell-free macrophage cytokines and eicosanoids in inhibiting tumor cell growth (Table 2).

TABLE 2

Effect on tumor growth of cytokine mediators produced by the macrophage and their interactions with eicosanoids.

Treatment

\begin{tabular}{|c|c|c|c|c|}
\hline \multicolumn{2}{|l|}{ Simultaneous ${ }^{\mathrm{a}}$} & \multicolumn{3}{|c|}{ Preconditioning } \\
\hline Compound ${ }^{b}$ & Inhibition $^{\mathfrak{c}}$ & Prior $^{d}$ & Simultaneous & Inhibition \\
\hline IL-1 & + & IL-1 & None & 0 \\
\hline $\mathrm{IL}-1+\mathrm{PGE}_{2}$ & ++ & IL-1 & $\mathrm{PGE}_{2}$ & ++ \\
\hline $\mathrm{IL}-1+\mathrm{PGI}_{2}$ & ++ & IL-1 & $\mathrm{PGI}_{2}$ & + \\
\hline IL-1 + LTC $_{4}$ & 0 & & & \\
\hline $\mathrm{TNF} \alpha$ & + & $\mathrm{TNF} \alpha$ & None & 0 \\
\hline $\mathrm{TNF} \alpha+\mathrm{PGE}_{2}$ & ++ & $\mathrm{TNF} \alpha$ & $\mathrm{PGE}_{2}$ & ++ \\
\hline $\mathrm{TNF} \alpha+\mathrm{PGI}_{2}$ & + & TNF $\alpha$ & $\mathrm{PGI}_{2}^{2}$ & 0 \\
\hline
\end{tabular}

a Compounds added simultaneously with WEHI-3B tumor cells to culture medium. b IL-1: $1000 \mathrm{U} / \mathrm{ml} ; \mathrm{TNF} \alpha$ : $100 \mathrm{U} / \mathrm{ml}$; PGE : $^{2}$ $10^{-6} \mathrm{M} ; \mathrm{PGI}_{2}: 4 \times 10^{-8} \mathrm{M} ; \mathrm{LTC}_{4}: 10^{-7} \mathrm{M}$. PGE 2 alone has a slight cytostatic effect. $\mathrm{LTC}_{4}$ and $\mathrm{PGI}_{2}$ alone had no effect at the concentrations used. Higher concentrations of $\mathrm{PGI}_{2}$ markedly inhibited growth. ${ }^{\mathrm{c}}$ Inhibition calculated by comparison with ${ }^{3} \mathrm{H}$-thymidine incorporation in corresponding cultures of untreated tumor cells: rating of inhibition: $0-19 \%, 0 ; 20-39 \%,+;>40 \%,++. d$ Tumor cells were first incubated for $1 \mathrm{~h}$ with the compound and then washed before resetting in culture medium. Prior treatment with either one of the cytokines did not precondition to subsequent exposure to the same cytokine or to the other cytokine. Data on simultaneous treatment with IL-1 and eicosanoids are from reference 27 ; other data from reference 28. 
The cytostatic activity of HrIL-1 toward WEHI-3B tumor cells was enhanced by $\mathrm{PGE}_{2}$ or prostacyclin $\left(\mathrm{PGI}_{2}\right)$, whereas simultaneous addition of $\mathrm{LTC}_{4}$ prevented cytostasis by IL-1 [9]. A similar synergistic effect was found between $\mathrm{HrTNF} \alpha$ and $\mathrm{PGE}_{2}$, but not between TNF $\alpha$ and PGI [28]. Prior treatment with either IL-1 or TNF $\alpha$ rendered the tumor cells susceptible to $\mathrm{PGE}_{2}$, whereas only prior contact with IL-1 rendered the cells susceptible to $\mathrm{PGI}_{2}$ [28]. Therefore, whereas exogenous addition of prostaglandins was shown to inhibit the release of IL-1 $[15,16]$, these two products interact synergistically in enhancing antitumor cytostasis, when they are added as cell-free compounds to tumor-cell cultures. Moreover, exogenous addition of a leukotriene, $\mathrm{LTC}_{4}$, antagonized the cytostatic activity of IL-1, whereas endogenous release of leukotrienes favours cell-to-cell cytostasis $[9,11,22,23]$ and production of IL-1 [16]. In contrast to IL-1, TNF $\alpha$

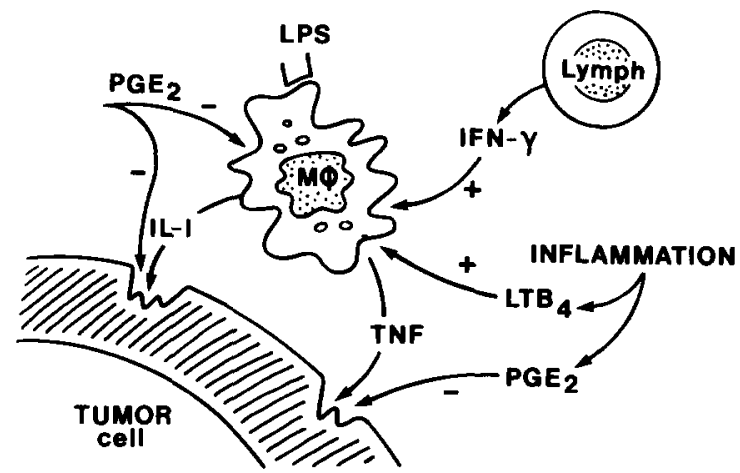

Fig. 2. Schematic view of some factors involved in the antitumor cytostatic function of macrophages from inflammatory environment. A premise in this concept is that the antitumor function of macrophages is unconditionally linked to activation of these cells. The macrophage cooperation with $\mathrm{T}$ cells is of importance, because the $T$ cell product interferon- $\gamma$ is a powerful activator of macrophages. Activated macrophages vigorously secrete IL-1 and TNF, which can inhibit the growth of several tumor cell lines. Infectious-inflammatory sites contain substantial amounts of bacterial endotoxins (symbolized here as LPS), which stimulate the secretion of IL-1 and TNF. Still another factor that causes the macrophage to secrete cytokines is the lipoxygenase product $\mathrm{LTB}_{4}$ which is abundantly present at sites of inflammation. The cyclooxygenase metabolite $\mathrm{PGE}_{2}$ has multiple roles in macrophage antitumor cytostasis: it counteracts the activation of macrophages and inhibits the secretion of cytokines. On the other hand $\mathrm{PGE}_{2}$ appears to directly inhibit the growth of some tumor cell lines and may have potentiating interactions with effects of the cytokines. This oversimplified model, in common with most models, is a poor replica of reality. did not act synergistically with $\mathrm{PGI}_{2}$ [28]. The difference between IL-1 and TNF $\alpha$ in interaction with prostaglandins may be due to differences in their mechanism of activity and/or to differences between $\mathrm{PGE}_{2}$ and $\mathrm{PGI}_{2}$ in their mode of activity. Differences between the activity of $\mathrm{PGE}_{2}$ and $\mathrm{PGI}_{2}$ were reported in context of regulation of macrophagemediated tumor killing [29]. Furthermore $\mathrm{PGE}_{2}$ itself acted in different ways in various experimental conditions. Increase in $\mathrm{PGE}_{2}$ production in activated macrophages resulted in inhibition of their tumoricidal activity, whereas production of high levels of $\mathrm{PGE}_{2}$ by resident and elicited macrophages was associated with increase in antitumor activity [30]. These results are all the more in variance with others because elicited macrophages are usually found to produce relatively low amounts of $\mathrm{PGE}_{2}$ [31].

\section{Ex-vivo human inflammatory macrophages}

The set of observations presented above led us to conclude that mediators of inflammation have a two-fold implication for the function of macrophages. First, when the balance of eicosanoid production profile of macrophages is tipped in favor of the lipoxygenase pathway, the macrophage becomes activated and displays improved cytostasis $[9$, 11]. The expression of this function may be even further improved by exposing the macrophage to a leukotriene $\left(\mathrm{LTC}_{4}\right.$ or $\left.\mathrm{LTD}_{4}\right)[22,23]$. Second, the direct antitumor cytostasis of macrophage-derived cytokines (IL-1 and TNF $\alpha$ ), can be modified by exogenous addition of eicosanoids in absence of macrophages, as published earlier (Ref. 27 and Table 2). Some macrophage-derived cytokines are recognized as mediators of inflammation [5] and as exerting antitumor activity $[25,26]$. Therefore, we addressed the question whether macrophages harvested from an inflammatory environment would express more antitumor cytostatic activity than macrophages harvested from an inflammation-free environment [32]. Human macrophages collected from dialysis bags during peritoneal inflammation exhibited markedly enhanced cytostatic activity (Table 3 ). Improved cytostasis was evident toward three target cell lines: one requiring cell-to-cell contact (MOPC-315), another which is sensitive to both IL-1 and TNF $\alpha$ (WEHI-3B), and a third cell line susceptible to 
Inflammatory environment enhances the antitumor cytostasis of human peritoneal macrophages ${ }^{\mathbf{a}}$.

\begin{tabular}{|c|c|c|c|c|}
\hline \multirow[t]{3}{*}{ Target cell line } & \multicolumn{4}{|c|}{ Inhibition of tumor-cell growth by macrophages of different environments ${ }^{b}$} \\
\hline & \multicolumn{2}{|c|}{ Non-inflammatory } & \multicolumn{2}{|l|}{ Inflammatory } \\
\hline & Unstimulated & LPS $^{c}$ stimulated & Unstimulated & LPS $^{c}$ stimulated \\
\hline MOPC-315 & 0 & 0 & ++ & ++ \\
\hline WEHI-3B & 0 & + & + & ++ \\
\hline L929 & 0 & ++ & + & ++ \\
\hline
\end{tabular}

a Human peritoneal macrophages were collected from patients on continuous peritoneal ambulatory dialysis (CAPD). ${ }^{\mathrm{b}} \mathrm{Macro-}$ phage/target-cell ratio was $100 /$, using the coculture method rating of inhibition: $0-19 \%, 0 ; 20-39 \%,+;>40 \%,++.{ }^{c}$ LPS, $0.5 \mu \mathrm{g} / \mathrm{ml}$. For more details see ref. 32 .

TNF $\alpha$ only (L929: transformed fibroblast line). Human peritoneal macrophages from an inflammatory environment display reduced basal release of $\mathrm{PGE}_{2}$, a circumstance that favors the activation of macrophages. Reduction in $\mathrm{PGE}_{2}$ production was also found to enhance cytostasis toward MOPC-315 tumor cells of mouse peritoneal macrophages [9, 23]. The fact that human peritoneal macrophages from an inflammatory environment exhibit cytostasis toward murine tumor cells, indicates that species differences play in this event a subordinate role. The present results (Table 3) also show that LPS enhances the cytostatic activity toward WEHI-3B and L929 cells of human macrophages from an inflammatory environment. It is worth mention in this context that LPS is a powerful stimulant of IL-1 discharge from human peritoneal macrophages, particularly those from an inflammatory environment [33], and that LPS induces production of TNF $\alpha$ [19]. Macrophages from inflammatory environments have a low level of cyclic AMP [34], and it is conceivable that their content of cyclic GMP is relatively high. A prevalence of cyclic GMP was recently shown to be associated with the release of TNF $\alpha[20]$.

\section{General remarks}

It has been well established that inflammatory mediators (cytokines and eicosanoids) regulate their own and each other's release. Our findings discussed here, indicate that they also interact in expression of antitumor cytostatic activity. Thus, indomethacin (a cyclooxygenase inhibitor) promotes antitumor ac- tivity of macrophages, not only by inhibiting endogenous production of $\mathrm{PGE}_{2}$, but also by increasing the production of leukotrienes. The use of tumor lines susceptible to cell-free cytokines IL-1 and TNF $\alpha$ enabled us to show interactions between exogenous cytokines and prostaglandins in the context of antitumor cytostatic activity. It is of interest in this respect that prostaglandins acted synergistically with macrophage cytokines in increasing antitumor activity, whereas an increase in endogenous production of prostaglandins is assumed to be correlated with a decrease in antitumor activity.

These results apply to in vitro or ex vivo systems of determination of antitumor activity. It might be of interest to determine to what extent mutual interactions between macrophage cytokines and eicosanoids play a role in the expression of antitumor effects of macrophages in vivo. Such information is not yet available. Nevertheless, our findings provide a link between the inflammation process and the antitumor activity of macrophages in the antitumor activity of macrophages in tumor-bearing individuals.

\section{Acknowledgements}

The authors' work is supported by the Dutch Cancer Society.

\section{References}

[1] Metchnikoff, E. (1901). L'Immunité dans les Maladies Infectieuses. Masson, Paris.

[2] Metchnikoff, E. (1915) Immunity in Infective Diseases. Cambridge University Press, Cambridge. 
[3] Ruco, L. P. and Meltzer, M. S. (1978) J. Immunol. 120, 1054.

[4] Adams, D. O. and Hamilton, F. A. (1988) in: Inflammation: Basic Principles and Clinical Correlates (J. I. Gallin, M. Goldstein and R. Snyderman, eds.) pp. 471-492. Raven Press, New York.

[5] Movat, H. Z. (1987) J. Lab. Clin. Med. 110, 668.

[6] Dinarello, C. A., Cannon, J. G., Mier, J. W., Bernheim, H. A., LoPreste, G., Lynn, D. L., Love, R. N., Webb, A. C. and Auron, P. E. (1986). J. Clin. Invest. 77, 1734.

[7] Bonta, I. L and Parnham, M. J. (1982) Int. J. Immunopharmacol. 4, 103.

[8] Farrar, W. L. and Humes, J. L. (1985) J. Immunol, 135, 1153.

[9] Elliott, G. R., Tak, C., Pellens, S., Ben-Efraim, S. and Bonta, I. L. (1988). Cancer Immunol. Immunother. 27, 133.

[10] Elliott, G. R., Lauwen, J. P. M. and Bonta, I. L. (1989). Br. J. Pharmacol. 96, 265.

[11] Van Hilten, J. A., Elliott, G. R. and Bonta, I. L. (1988) Prostagl. Leukotr. Essential Fatty Acids 34, 187.

[12] Feuerstein, N., Foegh, M. and Ramwell, P. W. (1981) Br. J. Pharmacol. 72, 389.

[13] Schenkelaars, E. J. and Bonta, I. L. (1986) Int. J. Immunopharmacol. 8, 305.

[14] Elliott, G. R., Van Batenburg, M. J. and Bonta, I. L. (1985). Eur. J. Pharmacol. 114, 71.

[15] Kunkel, S. L., Chensue, S. W. and Phan, S. H. (1986). J. Immunol. 136, 186

[16] Rola-Pleszczynski, M. and Lemaire, I. (1985). J. Immunol. 135,3958

[17] Otterness, I. G., Bliven, M. L., Eskra, J. D., Reinke, M. and Hansen, D. C. (1988). Cell Immunol. 114, 385.

[18] Dinarello, C. A., Cannon, J. G., Wolff, S. M., Bernheim, H. A., Beutler, B., Cerami, A., Figari, I. S., Palladino, M. A. and O'Connor, J. W. (1986). J. Exp. Med. 163, 1433.

[19] Carswell, E. A., Old, L. J., Kassel, R. L., Green, S., Fiore, N. and Williamson, B. (1975). Proc. Natl. Acad. Sci. USA
72, 3666.

[20] Renz, H., Gong, J. H., Schmidt, A., Nain, M. and Gemsa, D. (1988). J. Immunol. 141, 2388.

[21] Lepoivre, M., Boudbid, H., Lemaire, G. and Petit, J. F. (1988) Cell. Immunol. 115, 273.

[22] Gagnon, L., Fillion, L. G., Dubois, C. and RolaPleszczynski, M. (1989). Agents Actions 26, 141.

[23] Ophir, R., Ben-Efraim, S. and Bonta, I. L. (1987) Int. J. Tissue Reactions 9, 189.

[24] Opitz, H. G., Niethammer, D., Lemke, H., Flad, H. D. and Huget, R. (1975) Cell Immunol. 16, 379.

[25] Aggarwal, B. B. (1987) in: Drugs of the Future 12, 891.

[26] Onozaki, K., Matsushima, K., Aggarwal, B. B. and Oppenheim, J. J. (1985). J. Immunol. 135, 3962.

[27] Elliott, G. R., Tak, C. and Bonta, I. L. (1989). Cancer Immunol. Immunother. 28, 74 .

[28] Ben-Efraim, S., Tak, C. and Bonta, I. L. (1990). Prostagl. Leukotr. Essential Fatty Acids, in press.

[29] Taffet, S. M., Evrall, T. E. and Rusell, S. W. (1982). Prostaglandins 24, 763.

[30] Snyder, M. E., Fertel, R. H. and Zwilling, B. S. (1982). Cell Immunol. 74, 234.

[31] Humes, J. L., Sadouski, S., Galvage, M., Goldenberg, M., Subers, E., Bonney, R. J. and Kuehl, F. A. (1982). J. Biol. Chem. 257, 1591.

[32] Bonta, I. L., Ben-Efraim, S., Tak, C., Fieren, M. W. J. A. and Van den Bemd, G. J. C. M. (1990). In: Advances in Prostaglandins, Thromboxane and Leukotriene Research (B. Samuelsson, R. Paoletti and P. W. Ramwell, eds.) Vol. 18, (in press). Raven Press, New York'

[33] Fieren, M. W. J. A., Van den Bemd, G. J. C. M. and Bonta, I. L. (1990). Eur. J. Clin. Invest., in press.

[34] Adolfs, M. J. P., Fieren, M. W. J. A. and Bonta, I. L. (1985). Prostagl. Leukotr. Med. 18, 108.

[35] Dinarello, C. A. (1984). Rev. Inf. Dis. 6, 51. 